\title{
Immunolocalization of G Protein $\alpha$-Subunits in the Drosophila CNS
}

\author{
William J. Wolfgang, ${ }^{1, a}$ Franklin Quan, ${ }^{1}$ Paul Goldsmith, ${ }^{2}$ Cecilia Unson, ${ }^{3}$ Allen Spiegel, ${ }^{2}$ and Michael Forte ${ }^{1}$ \\ 'Vollum Institute For Advanced Biomedical Research, Oregon Health Sciences University, Portland, Oregon 97201 , \\ "Molecular Pathophysiology Branch, National Institutes of Diabetes and Digestive and Kidney Diseases, National Institutes \\ of Health, Bethesda, Maryland 20892, and 'Department of Biochemistry, Rockefeller University, New York, New York \\ 10021
}

In order to uncover the role of $\mathrm{G}$ proteins in the integrative functioning and development of the nervous system, we have begun a multidisciplinary study of the $G$ proteins present in the fruit fly, Drosophila melanogaster. In this report, we describe the distribution of 3 different $G$ protein $\alpha$-subunits in the adult Drosophila CNS as determined by immunocytochemical localization using affinity-purified antibodies generated to synthetic oligopeptide sequences unique to each $\alpha$-subunit. Western blot analysis of membranes prepared from Drosophila heads indicates that antibodies specific for the Drosophila Go $\alpha$ and Gs $\alpha$ homologs recognize the appropriate protein species predicted by molecular cloning (Quan et al., 1989; Thambi et al., 1989). The Gi $\alpha$ homolog could not be detected in head membranes by Western blotting, consistent with the negligible levels of expression observed for Gi $\alpha$ on Northern blots of head mRNA (Provost et al., 1988). However, a Drosophila Gi $\alpha$ fusion protein could be detected by these antibodies following expression in $E$. coli. Immunolocalization studies revealed that the Go $\alpha$ and Gs $\alpha$ homologs are expressed at highest levels in neuropils and at intermediate levels in the cortex of all brain and thoracic ganglion areas. Only the lamina contained low levels of these $\alpha$-subunits in the CNS. Additionally, Gs $\alpha$ appears to be associated with the cell membranes of neuronal cell bodies, while Go $\alpha$ has a more diffuse distribution, suggesting its presence in the cytoplasm as well as cell membranes. In contrast to the wide distribution of Go $\alpha$ and Gs $\alpha$, Gi $\alpha$ has a surprisingly restricted distribution in the CNS. It is present at high levels only in photoreceptor cell terminations, glomerulae of the antennal lobes, and the ocellar retina. Little or no Gi $\alpha$ was detected in other brain regions or in the thoracic ganglion. Gi $\alpha$, then, appears to be uniquely associated with some primary sensory afferents and their terminations, suggesting the presence of specific receptor and/or effector systems which mediate the transmission of primary sensory information in Drosophila.

$\mathrm{G}$ proteins are a family of molecules which couple receptors for hormones, neurotransmitters, and light to a number of effector systems in the generation second messengers within the cell (Gilman, 1984; Stryer and Bourne, 1986; Spiegel, 1987). The

\footnotetext{
Received June 12, 1989; revised Sept. 21, 1989; accepted Oct. 6, 1989.

This work was supported by grants from the NIH to M.F. F.O. is the recipient of a Canadian Medical Research Council Postdoctoral Fellowship.

Correspondence should be addressed to William J. Wolfgang at the above address.

Copyright (C) 1990 Society for Neuroscience $0270-6474 / 90 / 031014-11 \$ 02.00 / 0$
}

$\mathrm{G}$ protein molecule is a heterotrimer, consisting of $\alpha, \beta$, and $\gamma$ subunits. The $\beta / \gamma$ subunits are highly conserved between different $G$ proteins and are thought to function in anchoring the complex to the cell membrane. In contrast, the $\alpha$ subunits show much greater diversity and define the members of each family. For example, transducins $(\mathrm{Gt} \alpha)$ are responsible for the transduction of light in the retina to an activation of cGMP phosphodiesterase. Gs $\alpha$ and Gi $\alpha$ stimulate and inhibit the activity of adenyl cyclase, respectively (Gilman, 1984), and modulate the function of ion channels (Brown et al., 1989). Go $\alpha$, whose function has yet to be unequivocally determined, is an abundant $G$ protein of the nervous system (Neer et al., 1984; Sternweis and Robishaw, 1984). Molecular cloning of cDNAs coding for $\alpha$ subunits from a number of vertebrate (Itoh et al., 1986), invertebrate (Provost et al., 1988; Quan et al., 1989; Thambi et al., 1989) and unicellular organisms (Dietzel and Kurjan, 1987; Miyajima et al., 1987; Kumagai et al., 1989) has revealed a high degree of evolutionary conservation and also has demonstrated that distinct molecular forms exist between and within each functional class of $\alpha$ subunit. The significance of these alternate forms is unclear.

The study of $\mathrm{G}$ proteins has been limited primarily to conventional in vitro biochemistry and the genetic manipulation of cultured cells. These studies have led to a good understanding of some of the catalytic functions of the various types of $G$ proteins within the context of these systems. However, since $G$ proteins are a common intermediary between the activation of many types of receptors and a number of effector molecules, they are in a unique position to regulate cellular responsiveness to a wide variety of extracellular signals encountered in the organism. Consequently, $G$ proteins may play essential roles in complex neuronal functions, developmental processes, and other cellular activities coordinated through intracellular signals. The role of $G$ proteins in these complex biological functions can be meaningfully studied at the present time only in intact organisms.

In order to uncover the role of $G$ proteins in such processes, we have begun to characterize the $G$ proteins present in the fruit fly Drosophila melanogaster, an organism amenable to a variety of experimental approaches, including genetics. Recently, Drosophila cDNAs have been identified which code for proteins with high sequence similarity to vertebrate Gs $\alpha$, Gi $\alpha$ and Go $\alpha$ (Provost et al., 1988; Quan et al., 1989; Thambi et al., 1989). Comparison of the derived amino acid sequence of these proteins indicates that domains uniquely found in each $\alpha$ subunit class are conserved between Drosophila and vertebrates. For example, the C-terminal 21 residues of vertebrate and Dro- 
sophila Gs $\alpha$ are identical. In vertebrates, these unique regions of each $\alpha$ subunit are thought to mediate the specific functions of each $\mathrm{G} \alpha$. Peptides corresponding to regions which differ between each $\mathrm{G} \alpha$ class have also been used to generate antibodies which will discriminate not only $\alpha$ subunits in different classes but different members within each class (Goldsmith et al., 1987, $1988 \mathrm{a}, \mathrm{b})$. In this report, we demonstrate that as predicted, these peptide specific antibodies will recognize proteins on Western blots which correspond to several forms of $\mathrm{G} \alpha$ expressed in the adult Drosophila nervous system. These antibodies have then been used to examine the distribution of $3 \mathrm{G} \alpha$ subunits (Gs, Go, Gi) in the Drosophila CNS by light-level immunohistochemistry. The fly CNS provides a good system for such a study since it is organized as a cellular cortex whose processes form a modest number of interconnected fibrous neuropils (synaptic nuclei), many of which (particularly sensory) have known functions (Power, 1943; Strausfeld, 1976). Thus, in Drosophila, variation in G-protein distribution may be tentatively correlated to different functional requirements in that region of the CNS. For instance, our results show Go $\alpha$ and Gs $\alpha$ homologs are abundant in all neuropils in the CNS except the lamina (first-order optic neuropil). Surprisingly, the Gi $\alpha$ homolog is preferentially expressed in regions containing the terminations of primary sensory afferents, suggesting the involvement of specific receptor and/or effector in the transduction of primary sensory stimuli in Drosophila.

\section{Materials and Methods}

Nomenclature. For convenience, the vertebrate nomenclature (Gs $\alpha$, Gi $\alpha$, $\mathrm{Go} \alpha$ ) is used throughout this report to refer to the 3 identified Drosophila homologs. However, this does not necessarily imply any functional similarity since such studies have yet to be performed in Drosophila.

Fly cultures. Canton S flies were grown on artificial diet (Carolina Biological) at $19^{\circ} \mathrm{C}$. In all experiments, to control for sexual dimorphisms only well-fed female flies were selected 2-10 d after eclosion.

Primary antibodies. The $\mathrm{G}$ protein antibodies were made in rabbits against synthetic oligopeptides corresponding to sequences of mammalian $\mathrm{G}$ protein $\alpha$ subunits listed in Table 1. All antibodies were then affinity-purified as described by Goldsmith et al. (1987). Table 1 lists each of the peptides used as immunogens and the position of the corresponding sequence in vertebrate and Drosophila $\mathrm{G} \alpha$ subunits.

Western blot. Crude Drosophila head membranes (Thambi et al., 1989) and bovine brain cholate extracts (Goldsmith et al., 1988a) were prepared as previously described. Equal amounts $(1.8 \mathrm{mg})$ of bovine brain membrane cholate extract and crude adult Drosophila head membranes were applied to laneless $4 \mathrm{~cm}$ blocks of a $10 \%$ acrylamide/ $/ .13 \%$ bis-acrylamide SDS gel. After resolution by SDS-gel electrophoresis, proteins were transferred to nitrocellulose paper and strips cut for incubation with individual antisera for $1 \mathrm{hr}$ at room temperature. Primary antibody was localized using peroxidase-conjugated goat anti-rabbit Ig and 4-chloronaphthol as a substrate (Goldsmith et al., 1987, 1988a, b).

Immunohistochemistry. To permit adequate fixation, heads and thoraxes were separated and the mouthparts and air sacs removed from the head. The dorsal half of the thorax was also removed. The tissue was fixed in periodate-lysine-paraformaldehyde (McLean and Nakane, 1974) for $2 \mathrm{hr}$ at room temperature, transferred to $10 \%$ sucrose in 37

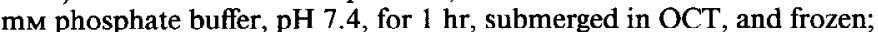
$6 \mu \mathrm{m}$ cryostat sections were then prepared. Sections were collected on gelatin-coated slides and fixed for an additional 20 minutes $-1 \mathrm{hr}$. Slides werc then blocked in 10\% horse serum (HS) and incubated in primary antibody overnight at $4^{\circ} \mathrm{C}$. Antibodies were diluted in $10 \% \mathrm{HS}$ to a working concentration of $0.25 \mu \mathrm{g} / \mathrm{ml}$ anti-RM, $0.66 \mu \mathrm{g} / \mathrm{ml}$ anti-LD, and $0.77 \mu \mathrm{g} / \mathrm{ml}$ anti-GO. In control experiments, the appropriate peptide was added to the diluted antibody to a final concentration of $10 \mu \mathrm{g} / \mathrm{ml}$ and incubated for $1 \mathrm{hr}$ at room temperature prior to application to slides. Slides were then rinsed in 3 changes of wash buffer $(0.1 \% \mathrm{NP}$ $40,0.1 \% \mathrm{BSA}, 0.5 \mathrm{M} \mathrm{NaCl}, 0.01 \mathrm{M} \mathrm{PO}_{4}, \mathrm{pH} 7.4$ ) over 15 minutes and then transferred to biotinylated second antibody $(7.5 \mu \mathrm{g} / \mathrm{ml}$; Vector Laboratories) in $10 \% \mathrm{HS}$ at room temperature for $0.5 \mathrm{hr}$. The slides
Table 1. Peptide sequences

\begin{tabular}{|c|c|c|c|}
\hline $\begin{array}{l}\alpha \\
\text { Subunit }\end{array}$ & $\begin{array}{l}\text { Anti- } \\
\text { body }\end{array}$ & Peptide immunogen ${ }^{a}$ & $\begin{array}{l}\text { Homologous } \\
\text { Drosophila } \\
\text { sequences }\end{array}$ \\
\hline Gro & GO & ${ }^{345}$ ANNLRGCGLY ${ }^{354}$ & ${ }^{345}$ ANNLRGCGLY $^{354}$ \\
\hline Gs & RM & ${ }^{385}$ RMHLRQYELL $^{394}$ & ${ }^{376}{ }^{\text {RMHLRQYELL }}{ }^{385}$ \\
\hline Gil & LD & ${ }^{159}$ LDRIAQPNYI $^{168}$ & ${ }^{160}$ LDRIAQPNYI ${ }^{169}$ \\
\hline
\end{tabular}

Based on mammalian sequence.

were washed and then incubated in peroxidase-conjugated $\mathrm{ABC}$ "elite" solution (Vector Laboratories) diluted 1:100 in 10\% HS for 15 minutes. Peroxidase activity was localized by incubation in $1 \mathrm{mg} / \mathrm{ml}$ diaminobenzidine (DAB) (Sigma), 0.01\% $\mathrm{H}_{2} \mathrm{O}_{2}, 0.1 \mathrm{M}$ phosphate buffer, $\mathrm{pH} 7.4$, for $5 \mathrm{~min}$. The $\mathrm{DAB}$ reaction product was further intensified by brief treatment with $0.1 \% \mathrm{OsO}_{4}$. Slides were then dehydrated and mounted.

Construction of Drosophila Gia expression vectors. Drosophila Gi $\alpha$ was expressed in $E$. coli as a fusion protein with the bacteriophage T7 major capsid protein using the vector pET3c (Rosenberg et al., 1987). This vector places the expression of the fusion protein under the control of the promoter for T7 RNA polymerasc. A $1.3 \mathrm{~kb}$ BstBI-HincII fragment containing sequences from $5 \mathrm{bp}$ upstream of the translation initiation codon to $223 \mathrm{bp}$ downstream of the termination codon was isolated from a full-length Drosophila Gi $\alpha$ cDNA and subcloned into the SmaI site of pKK223-3 (Pharmacia). Gi $\alpha$ coding sequences were liberated from pKK223-3 by digestion with HindIII followed by partial digestion with $E c o$ RI. The resulting EcoRI-HindIII fragment was endfilled with the Klenow fragment of DNA polymerase I in the presence of all 4 deoxynucleoside triphosphates. pET3c was cut with $B a m \mathrm{HI}$, end-filled with Klenow fragment, treated with calf alkaline phosphatase and ligated to the Gi $\alpha$ restriction fragment. Following transformation into $E$. coli $\mathrm{MC} 1061$, plasmid DNA was prepared and the presence and orientation of $\mathrm{Gi} \alpha$ inserts determined by restriction mapping. pET3c/ DGi $\alpha+$ and pET3c/DGi $\alpha$ - carry Gi $\alpha$ sequences in the sense and antisense orientations relative to the T7 RNA polymerasc promotcr, rcspectively. pET3c/DGi $\alpha+$ codes for a Gi $\alpha$ protein with a derived molecular weight of 42,731 containing an amino-terminal extension of 17 amino acid residues relative to Drosophila Gi $\alpha ; 12$ correspond to the amino terminus of the $\mathrm{T} 7$ gene 10 major capsid protein and 5 (Ile-AsnSer-Pro-Lys) derive from vector linker sequences and residual Gi $\alpha 5^{\prime}$ untranslated sequences.

Expression and detection of recombinant Gi $\alpha$. Recombinant Gi $\alpha$ was expressed in $E$. coli BL21(DE3)pLysE, a strain carrying a chromosomal T7 RNA polymerase gene under the control of the lacUV5 promoter (Studier and Moffatt, 1986) and harboring the plasmid pLysE. pLysE confers chloramphenicol resistance and provides the production of $\mathrm{T} 7$ lysozyme to inhibit T7 RNA polymerase produced in the absence of induction. $E$. coli BL21(DE3)pLysE, transformed with either pET3c/ DGi $\alpha+$ or - were used to inoculate $5 \mathrm{ml}$ cultures of LB medium containing $50 \mu \mathrm{g} / \mathrm{ml}$ ampicillin and $10 \mu \mathrm{g} / \mathrm{ml}$ chloramphenicol. Cultures were grown overnight and aliquots used to inoculate $50 \mathrm{ml}$ cultures. At $\mathrm{OD}_{600}=0.7$, the production of T7 RNA polymerase was induced by the addition of IPTG to a final concentration of $1 \mathrm{mM}$. After $2 \mathrm{hr}$ of induction, $2 \mathrm{ml}$ samples were withdrawn, and cells were harvested by centrifugation and lysed in SDS sample buffer by incubation in a boiling water bath for 5 minutes. Samples (10-20 $\mu$ l) were then resolved by electrophoresis on SDS-gels and transferred to nitrocellulose as described previously. Binding of LD antibody was localized using alkaline phosphatase-conjugated goat anti-rabbit IgG and nitro blue tetrazolium and 5-bromo-4-chloro-3-indolyl phosphate as substrates.

\section{Results}

Western blot analysis

As shown in Table 1, peptide sequences which have been used to generate $\mathrm{G} \alpha$-specific antisera in vertebrates are conserved in the various Drosophila $\mathrm{G} \alpha$ proteins. Northern blot analysis and in situ hybridization to tissue sections using $\alpha$ subunit-specific probes have indicated that Gs $\alpha$ and Go $\alpha$ are abundantly expressed in the adult nervous system (Quan et al., 1989; Thambi et al., 1989), while the Gi $\alpha$ gene product is present at extremely 
a

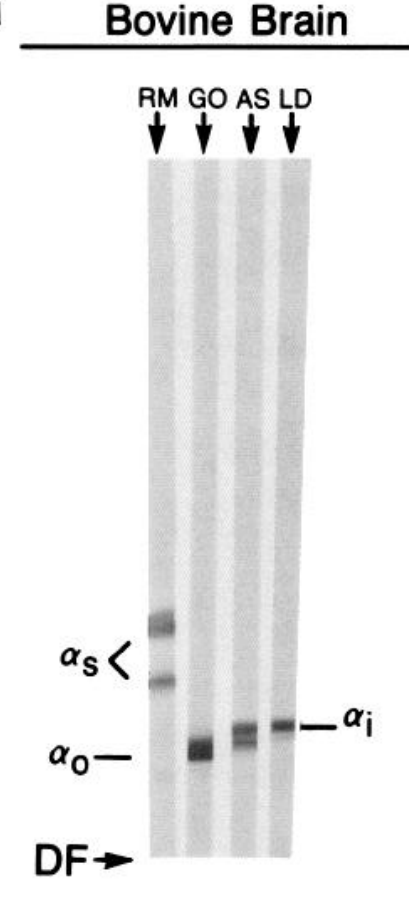

b Drosophila Head

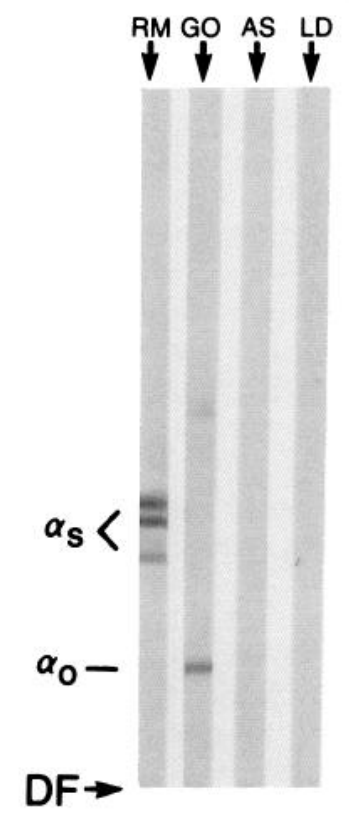

Figure 1. Immunoblot analysis of $\mathrm{G}$ proteins in adult Drosophila head and bovine brain membranes. $a$ and $b$, Strips were incubated with $\mathrm{RM}, 10 \mu \mathrm{g} / \mathrm{ml}$ affinity-purified antibody specific for Gs- $\alpha$; GO, 1/250 dilution crude antiserum specific for Go- $\alpha$; AS, $1 \mu \mathrm{g} / \mathrm{ml}$ affinity-purified antibody specific for Gt-, Gil-, and Gi2- $\alpha$; LD, $2 \mu \mathrm{g} / \mathrm{ml}$ affinity-purified antibody specific for Gil- $\alpha$. The entire immunoblot strip is shown, and the positions of Gs-, Go-, and $\mathrm{Gi}-\alpha$ subunits are indicated. $D F$, dye front. $c$, Nitrocellulose strips of Drosophila head membranes were incubated either with RM, $10 \mu \mathrm{g} / \mathrm{ml}$ affinity-purified antibody specific for Gs- $\alpha$, or with GO, 1/250 dilution of crude antiserum specific for Go- $\alpha$. First antibody solutions in which strips were incubated contained either no peptide (C) or 1 and $10 \mu \mathrm{g} / \mathrm{ml}$ final concentration ( 1 and 10 , respectively) of the synthetic peptides RMHLRQYELL $(R M)$ and ANNLRGCGLY $(G O)$ used to produce the respective peptide antisera. Only the portion of the strips containing the Gs- and Go- $\alpha$ subunits (indicated) is shown. low levels (Provost et al., 1988; W. J. Wolfgang, unpublished observations). Thus, membranes prepared from adult Drosophila heads should minimally contain proteins which are recognized by the Gs $\alpha$ and Go $\alpha$ peptide-specific antibodies listed in Table 1. Immunoblots of crude membranes prepared from adult heads were probed with the various antisera. In parallel, immunoblots of bovine brain membranes were probed with the same antisera. The proteins recognized by these antisera in bovine membranes have been well characterized. For example, the RM antisera, generated to sequences specifically found at the C-terminus of vertebrate Gs $\alpha$, identifies proteins of 43 and $48 \mathrm{kDa}$ in bovine brain membranes corresponding to the alternatively spliced forms of this $\mathrm{G} \alpha$ in vertebrates (Fig. 1 $a$, lane 1; Bray et al., 1986). In Drosophila, at least 3 distinct proteins, each larger than the equivalent vertebrate forms, are detected by the RM antibodies (Fig. 1 $b$, lane 1). The GO antiserum recognizes a $39 \mathrm{kDa}$ protein corresponding to $\mathrm{Go} \alpha$ in bovine brain membranes (Fig. 1 $a$, lane 2). A protein of equivalent size is identified by this antiserum in Drosophila (Fig. 1b, lane 2).

The specific binding of the RM and GO antibodies to Drosophila proteins was demonstrated by preincubation of these antibodies with peptides prior to incubation with immunoblots of Drosophila head membranes. For both antibodies, immunoreactivity was abolished by preincubation with as little as 1 $\mu \mathrm{g} / \mathrm{ml}$ of the cognate peptide (Fig. $1 c$, lanes $2,3,9,10$ ). Antibody binding was unaffected by the addition of as much as $10 \mu \mathrm{g} / \mathrm{ml}$ of each unrelated peptide (Fig. $1 c$, lanes $4,5,6,7$ ).

Two antisera were tested for their ability to recognize the Drosophila $\mathrm{Gi} \alpha$ homolog in membranes prepared from adult Drosophila heads. AS antibodies were generated to a peptide (KENLKDCGLF) representing the C-terminal decapeptide of vertebrate $\mathrm{Gt} \alpha$. This antiserum will also recognize vertebrate Gi $1 \alpha$ and Gi $2 \alpha$ (terminal decapeptide KNNLKDCGLF; Goldsmith et al., 1987, 1988a). The C-terminal decapeptide of the 
Drosophila Gi $\alpha$-like protein differs (underlined) by 2 residues from the Gil $\alpha$ and Gi2 $\alpha$ peptide (KNNLKQIGLF). No ASimmunoreactive proteins were detected in Drosophila head membranes (Fig. 1 $b$, lane 3 ) under conditions which allow ready detection of Gi $\alpha$ proteins in bovine brain membranes (Fig. 1a, lane 3). LD antibodies were generated to a sequence of Gil $\alpha$ (Goldsmith et al., 1988a) which is totally conserved in the Drosophila Gi $\alpha$ homolog (Table 1) (Provost et al., 1988). Again, no LD-immunoreactive proteins were observed in Drosophila (Fig. $1 b$, lane 4) under conditions which allow the detection of the $41 \mathrm{kDa}$ Gil $\alpha$ protein in bovine brain (Fig. $1 a$, lane 4 ). In addition, no AS- or LD-immunoreactive proteins were observed in nonmembrane fractions prepared from Drosophila heads (data not shown). Other antisera generated to peptides specific for vertebrate $\mathrm{Gi} 3 \alpha$ and $\mathrm{Gz} \alpha$ also failed to recognize Drosophila neuronal proteins (data not shown).

In order to demonstrate that the LD antibodies recognize Drosophila $\mathrm{Gi} \alpha, \mathrm{Gi} \alpha$ protein was expressed in $E$. coli as a fusion protein with the bacteriophage T7 major capsid protein as described in the Materials and Methods. The resulting Drosophila Gi $\alpha$ protein contains an amino-terminal extension of 17 residues relative to the native protein. As shown in Figure 2, lane 2, cell extracts prepared from $E$. coli expressing this fusion protein contain a single major LD-immunoreactive protein of appropriate molecular weight. Lower-molecular-weight immunoreactive bands are likely to represent proteolytic fragments of the main Gi $\alpha$ fusion protein. This protein is not present in extracts prepared from cells containing Gi $\alpha$-coding sequences in the reverse orientation (Fig. 2, lane 1). The specific binding of the LD antibodies to this fusion protein was abolished by preincubation of the antibodies with LD peptide (Fig. 2, lane 3). No reaction is seen when the LD antibody is omitted (Fig. 2, lane 4).

\section{Distribution of $\mathrm{G} \alpha$ proteins in the brain and thoracic ganglion of Drosophila \\ Gs $\alpha$}

The distribution of Gs $\alpha$ homolog was examined immunohistochemically using the RM antibodies in horizontal sections of the brain and thoracic ganglion (Fig. 3, $a, c$ ) and compared with control sections (Fig. $3 b$ ) in which the antibody had been preincubated with the peptide immunogen. In all experiments, control slides were similar in staining to slides in which the primary antibody was omitted. The most intense staining was in the neuropils of the CNS (Fig. $3 a, c, d$ ), which contains the axons, fiber tracts, and synapses with much less staining in the outer cortical regions containing the neuronal cell bodies. Staining of the cell bodies was strongest in the cortex of the cells (Fig. $3 d$, see arrow), presumably indicating the association of this protein with the cell membrane. The cortex and neuropil of the lamina (first-order optic neuropil) contained low levels of staining, while the first optic chiasma (between the lamina and medulla) and retina did not stain above background levels (cf. Fig. 3, $a, b$ ). The outer portion of the medulla (second optic neuropil) had a patchy distribution associated with the medullary cartridges. The thoracic ganglion has a similar distribution of staining in that the neuropil stains most strongly (Fig. 3c). Staining in the cortical region was possibly associated with cell membranes. The antibody also stains the basement membrane of the muscles in the head and thorax. A subset of antennal nerve fibers stains strongly (Fig. $4 d$ ), while the ocellar retina and ocellar nerve show only low staining (Fig. 4a).

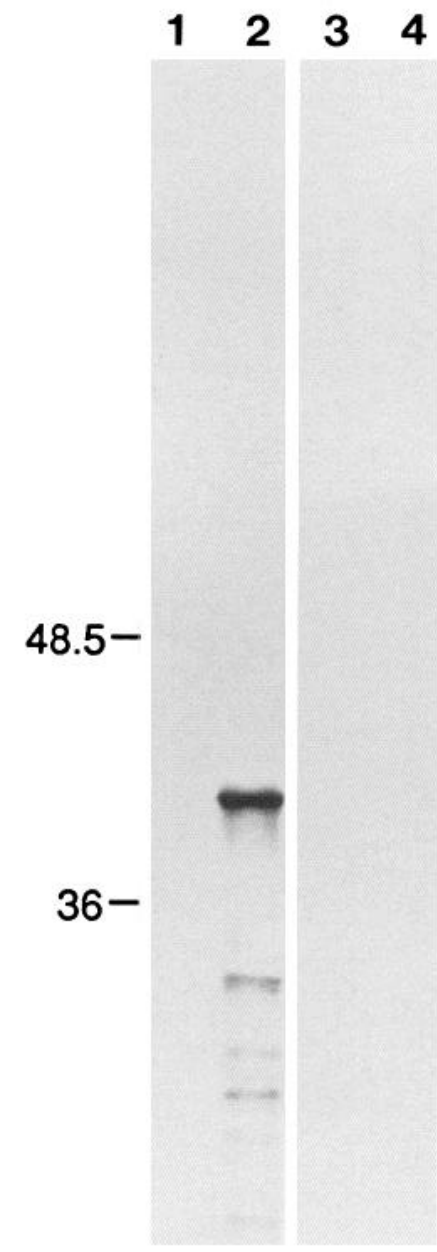

Figure 2. Immunoblot analysis of Drosophila Gi $\alpha$ protein expressed in E. coli. Drosophila Gi $\alpha$ coding sequences were subcloned into the expression vector pET3c in the sense $(+)$ and antisense $(-)$ orientation and expressed in E. coli as described in Materials and Methods. Samples representing total $E$. coli proteins were then resolved by electrophoresis on $10 \%$ SDS gels, transferred to nitrocellulose, and probed with the LD antibody $(0.66 \mu \mathrm{g} / \mathrm{ml})$. Lane 1 , protein from cells containing $\mathrm{pET} 3 \mathrm{c} /$ DGi $\alpha$-; lane 2, protein from cells containing pET3c/DGi $\alpha+$; lane 3 , protein from cells containing pET3c/DGi $\alpha+$ probed with LD antibodies which had been preincubated with 10 -fold excess LD peptide; lane 4 , protein from cells containing pET3c/DGi $\alpha+$ probed with secondary antibody alone. The migration of relevant molecular-weight markers is indicated.

Goo

In most cases, the distribution of the Go $\alpha$ homolog as detected by $\mathrm{GO}$ antibodies was quite similar to that observed for Gs $\alpha$ (Fig. 5, $a, c, d$ ). The neuropils of the brain and thoracic ganglion stain strongly, while the cortical regions contained moderate levels of antigen compared with controls. In the cell bodies of the neurons, Go $\alpha$ appeared more diffuse than Gs $\alpha$ and was not preferentially associated with the cell cortex. Unlike Gs $\alpha$, some cell bodies in the distal portion of the lamina contained Go $\alpha$, as well as a band of dots in the synaptic zone of the lamina. The retina, first optic chiasma, and ocellus had no increased staining compared with controls (Figs. $4 b, 5$ ). The distal half of the ocellar nerve had no staining, while the proximal half showed moderate levels of staining (Fig. 4b). The distribution of Go $\alpha$ in the outer layers of the medulla reflects its columnar organi- 


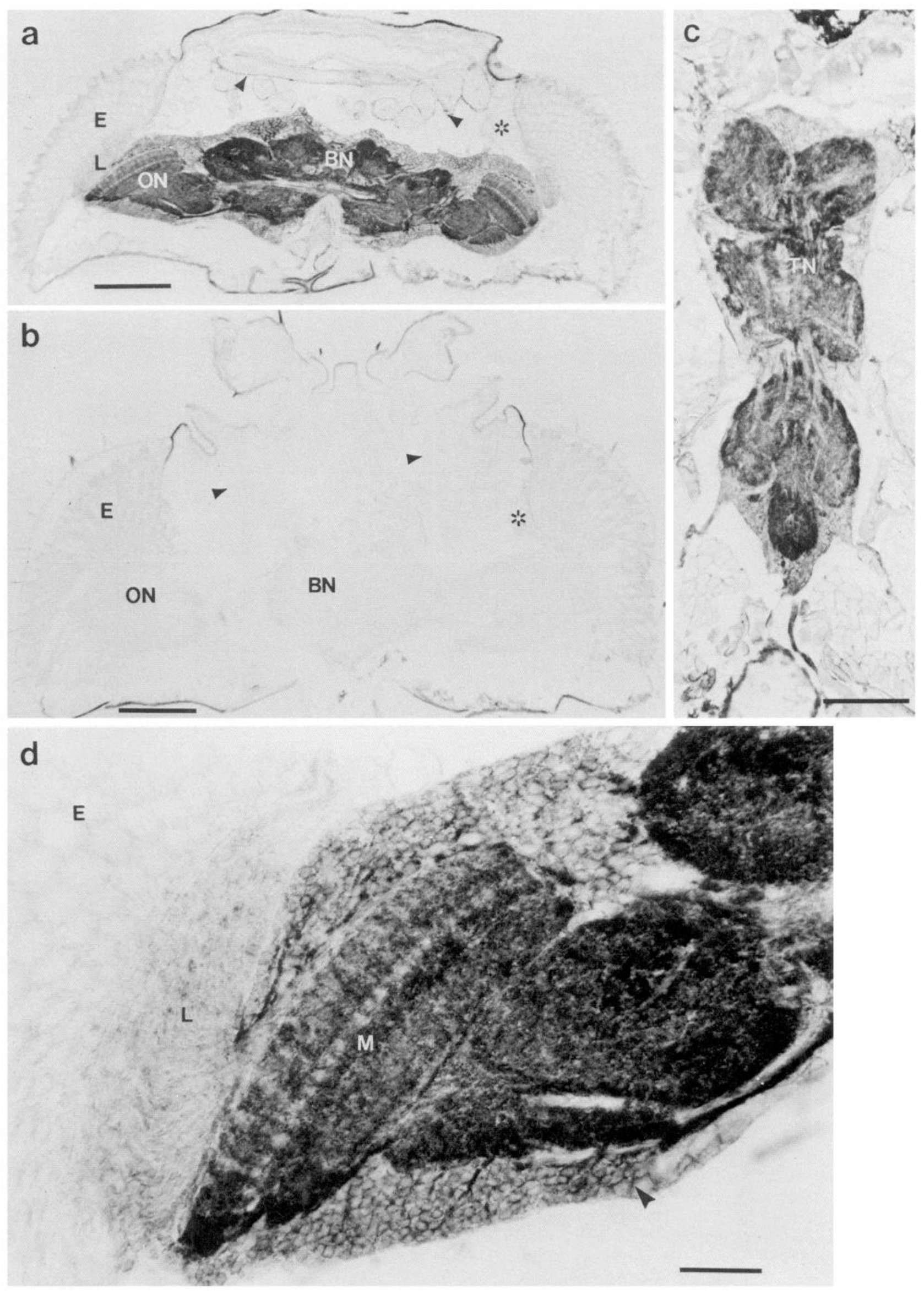



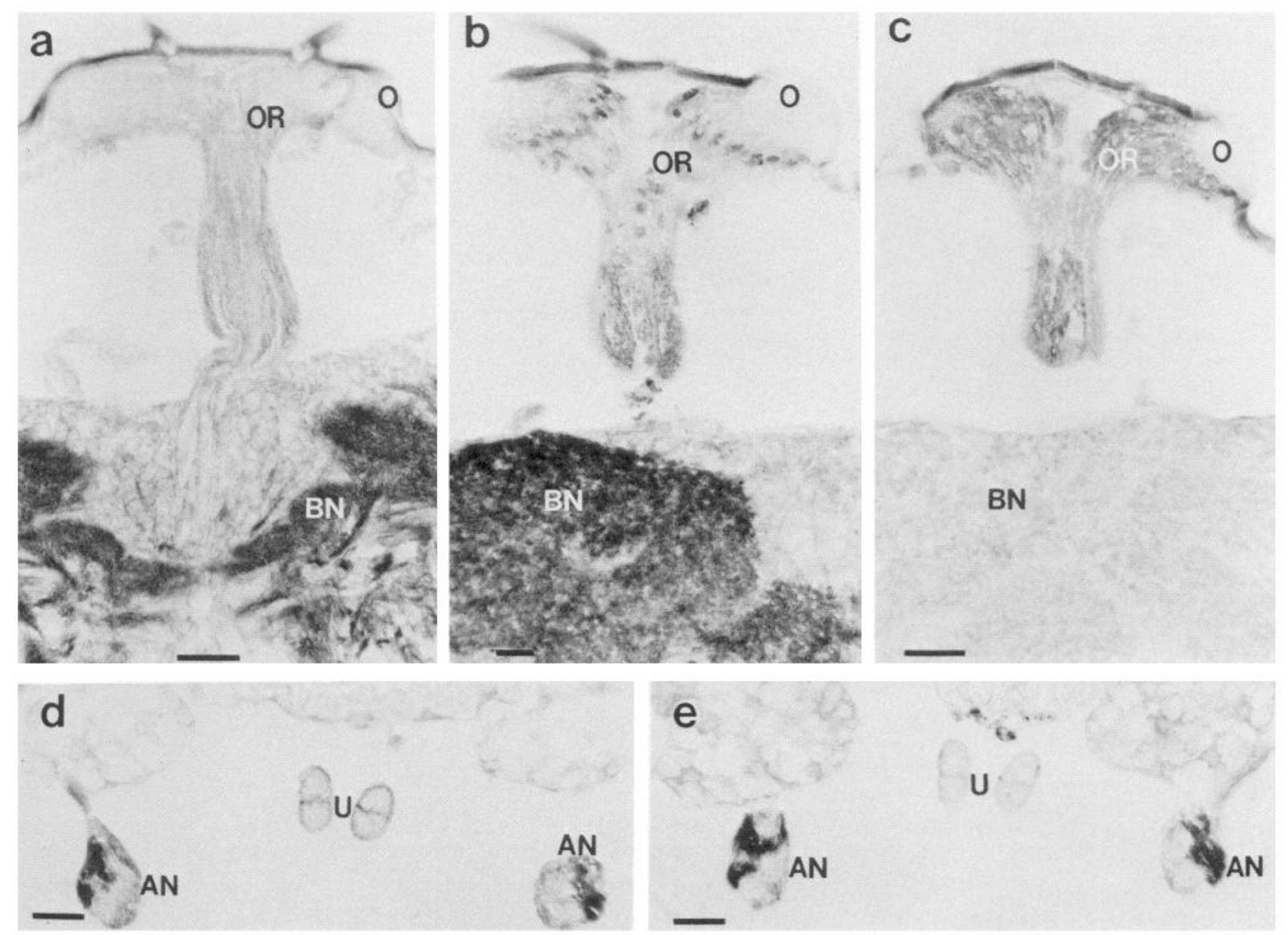

Figure 4. $a-c$, Frontal section through the ocelli and ocellar nerve stained for $(a) \mathrm{Gs},(b) \mathrm{Go}$, and $(c)$ Gi. Note that only Gi stains in the region of the ocellar retina. Go and Gs show generally low levels of staining in the ocellus except the staining of nuclei by Go. Scale bar, $20 \mu \mathrm{m}$. $d$ and $e$, Nearly adjacent transverse sections of the antennal nerve in which $(d)$ Go or $(e)$ Gs has been localized. Both proteins appear to be restricted to the same subset of axon bundles within the nerve. Scale bar, $20 \mu \mathrm{m}$. Gi did not stain the antennal nerve. $O$, ocellus; $O R$, ocellar retina; $B N$, brain neuropil; $A N$, antennal nerve; $U$, unidentified nerve.

zation (Fig. 5d) and appears less random than that of Gs $\alpha$ (Fig. $3 d$ ). The same bundle of axons in the antennal nerve that stained for Gs $\alpha$ also stained intensely for $\mathrm{Go} \alpha$ (Fig. 4e). The basal lamina of the muscle did not stain, and there appeared to be some specific staining of the fat body compared with controls (Fig. 5, $a, b)$.

Gix

As shown in Figure 1, antibodies generated to peptide sequences present in the Drosophila Gi $\alpha$-like protein fail to detect proteins on immunoblots of head membrane proteins but do detect Drosophila Gi $\alpha$ expressed in E. coli (Fig. 2). In tissue sections, LD antibodies stain specific neuronal structures (Fig. 6a). No staining was observed if the LD antibody was preincubated in the presence of $10 \mu \mathrm{g} / \mathrm{ml}$ of LD peptide (cf. Fig. $6, a, b$ ). No reduction in staining was detected if the antibody is preincubated with either the RM peptide (Fig. $6 c$ ) or the GO peptide (Fig. $6 d$ ). Thus, the LD antibodies specifically recognize an LD peptidecontaining antigen in the Drosophila nervous system and the Drosophila $\mathrm{Gi} \alpha$ homolog expressed in E. coli.

$\mathrm{Gi} \alpha$ distribution was markedly different in the brain and thoracic ganglion from either Gs $\alpha$ or Go $\alpha$. In general, uniformly low levels of $\mathrm{Gi} \alpha$ reactivity are detected throughout the CNS in both the cortex and neuropil (Fig. 6, $a, e$ ). Regions of fiber tracts show even less staining. Only at the termination of photoreceptor cells $1-6$ in the lamina and 7 and 8 in the medulla were high levels of staining observed (Figs. $6 a, 7 b$ ). Additionally, the glomerulae of the antennal lobes had a patchy distribution of in-

Figure 3. Localization of Gs $\alpha$ in horizontal sections through the brain and thoracic ganglion of an adult fly. $a$, Staining in the brain was greatest in the neuropil regions except the lamina. Scale bar, $100 \mu \mathrm{m}$. $b$, Control section in which the antibody was preabsorbed with the immunogen. The low levels of staining were equivalent to that seen when either the $1^{\circ}$ or $2^{\circ}$ antibodies were omitted. Photographs in $a$ and $b$, as well as all controls, were processed identically to facilitate comparisons. Scale bar, $100 \mu \mathrm{m}$. $c$, Staining in the thoracic ganglion, as in the brain, was greatest in the neuropil. Scale bar, $100 \mu \mathrm{m}$. $d$, High magnification of the left-hand optic lobe in $a$. Note the low staining in the lamina and the apparent cortical localization of Gs in the cell bodies of the neurons. Scale bar, $20 \mu \mathrm{m}$. $E$, eye; $B N$, midbrain neuropil; $O N$, optic lobe neuropil; $L$, lamina neuropil; $M$, medulla neuropil; $T N$, thoracic ganglion neuropil; arrowheads, basal lamina of muscles; asterisks, fat body. 


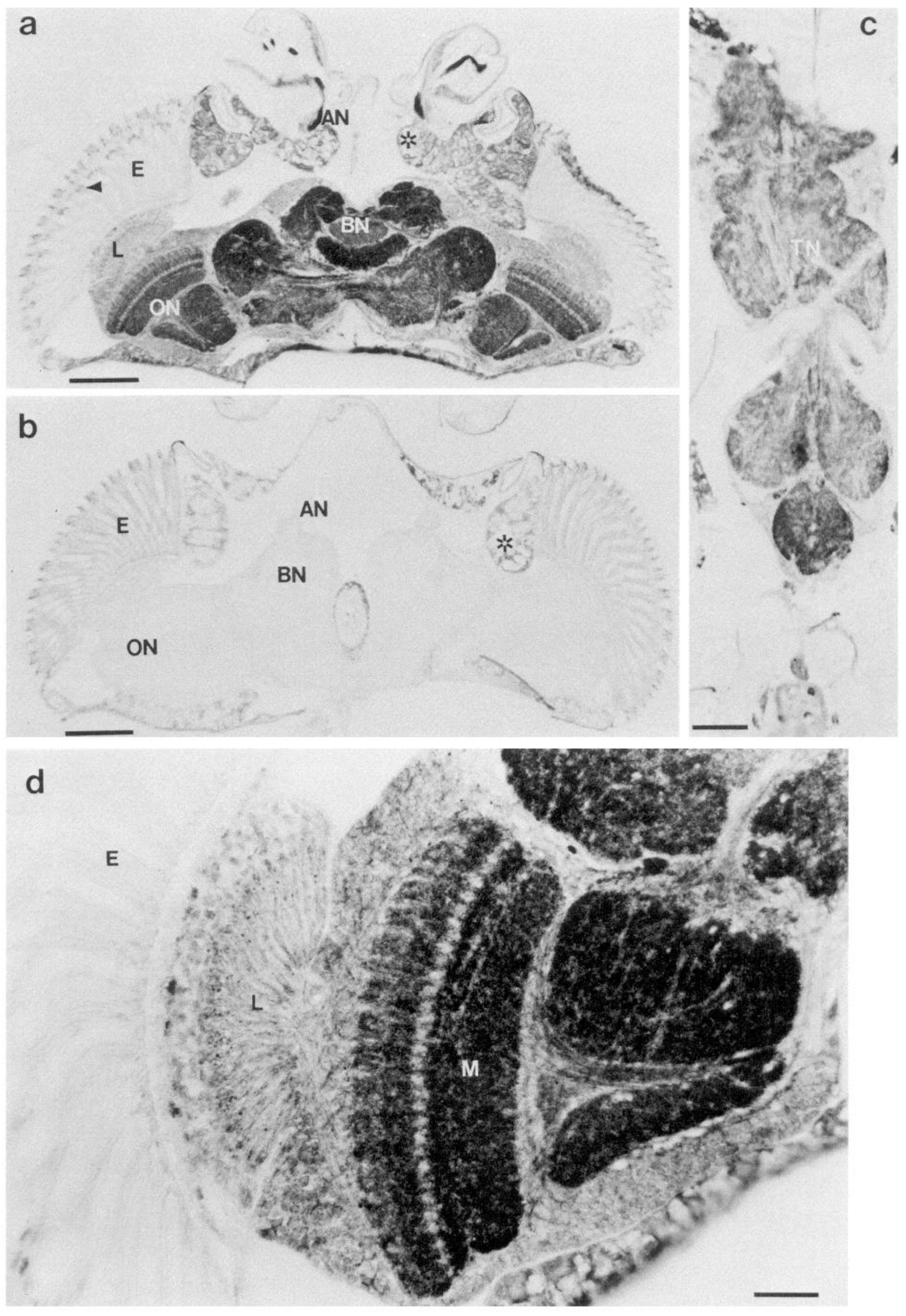




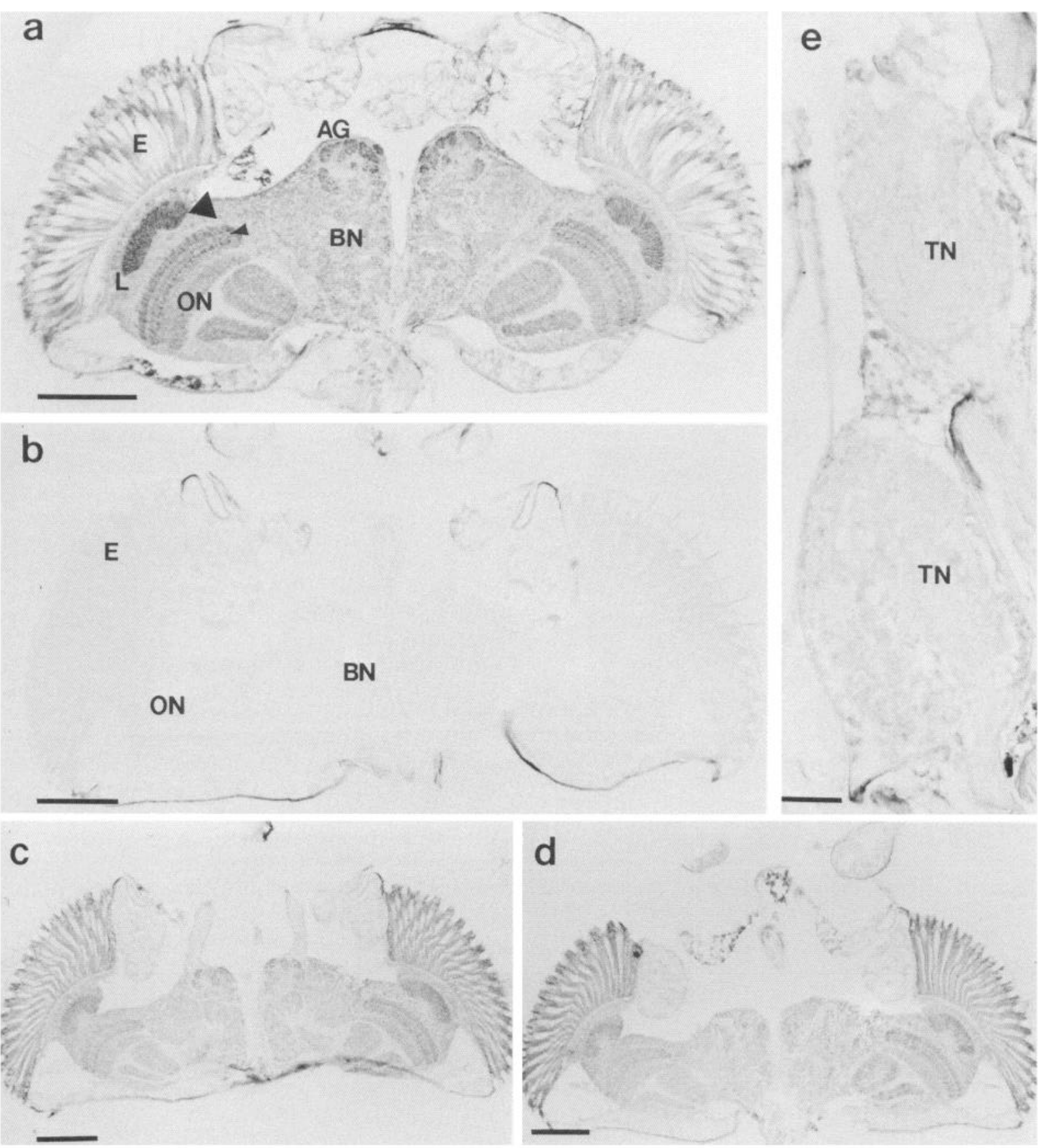

Figure 6. Localization of Gi $\alpha$ in the CNS of an adult fly using the antibody LD. $a$, Horizontal section through the brain. Gi is generally present at low levels except for intense staining at the terminations of photoreceptor cells 1-6 in the lamina and 7 and 8 in the medulla. Additionally, elevated staining was detected in the antennal glomerulae. Moderate levels of staining in the eye was associated with pigment cells. Scale bar, 100 $\mu \mathrm{m}$. $b$, Control section in which the antibody was preabsorbed with its immunogen. Scale bar, $100 \mu \mathrm{m}$. $c$ and $d$, preincubation of antibody with the Gs $(c)$ or the Go $(d)$ immunogen did not block Gi antibody staining. Scale bar, $100 \mu \mathrm{m}$. $e$, In a sagittal section of the thoracic ganglion, only low uniform levels of staining are detected. Scale bar, $50 \mu \mathrm{m}$. $E$, eye; $A G$, antennal glomerulae; $O N$, optic neuropil; $B N$, brain neuropil; $T N$, thoracic ganglion neuropil; big arrowhead, region of photoreceptor 1-6 terminations; small arrowhead, region of photoreceptor 7 and 8 termination.

Figure 5. Localization of Go $\alpha$ in horizontal sections of the brain and thoracic ganglion. $a$, In the brain, the greatest staining was in the neuropil regions with the exception of the lamina. Note also the intense staining in the antennal nerve [also seen with Gs (Fig. $3 d$ )] and, curiously, the staining of the nuclei of the photoreceptor and accessory cells in the eye. Additionally, the fat body shows elevated staining over controls. Scale bar, $100 \mu \mathrm{m} . b$. Control section in which the antibody was preabsorbed with $10 \mu \mathrm{g} / \mathrm{ml}$ of immunogen. The punctate staining in the eyes is associated with the distal portion of the pigment cells and not photoreceptor or accessory cell nuclei. Scale bar, $100 \mu \mathrm{m}$. $c$, Staining in the thoracic ganglion as in the brain was also greatest in the neuropil. Scale bar, $50 \mu \mathrm{m}$. $d$, High magnification of the left-hand optic lobe. Note the low staining in the lamina, as with Gs. However, in contrast to Gs, the apparent intracellular distribution of Go was diffuse and not associated with the cell cortex. Scale bar, $20 \mu \mathrm{m}$. $E$, eye; $O N$, optic lobe neuropil; $B N$, brain neuropil; $L$, lamina neuropil; $M$, medulla neuropil; $A N$, antennal nerve; $T N$, thoracic ganglion neuropil; asterisks, fat body; arrowhead, nuclei. 


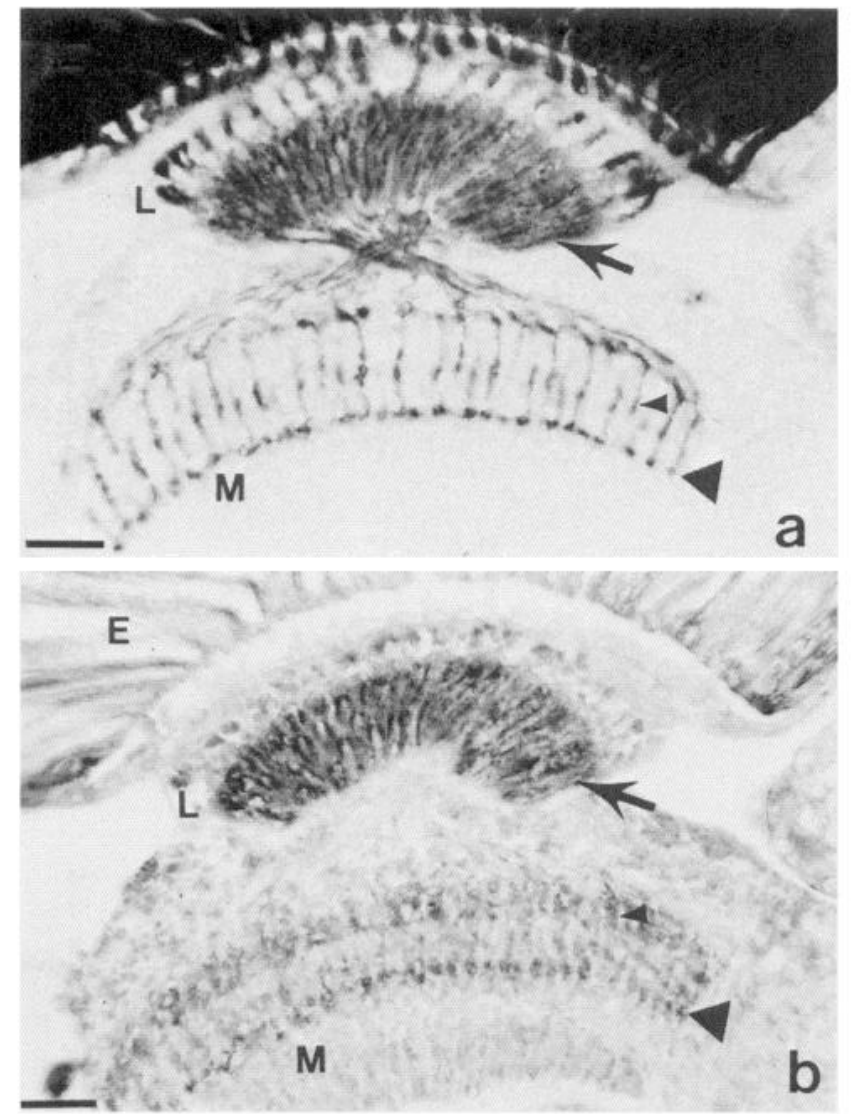

Figure 7. Adjacent horizontal sections (at $6 \mu \mathrm{m}$ ) through the optic lobe. $a$, Localization of chaoptin (Vactor et al., 1988) using the monoclonal antibody 24B10 diluted 1:10. Chaoptin is present only in the photoreceptor cells and their projections into the lamina and medulla. Scale bar, $20 \mu \mathrm{m}$. $b$, Adjacent section in which $\mathrm{Gi}$ has been localized. Comparing $a$ and $b$, it is clear that $\mathrm{Gi}$ is localized with the terminations of photoreceptor cells $1-6$ in the lamina and 7 and 8 in the medulla, though we cannot say if it is pre- or postsynaptic. Note the absence of $\mathrm{Gi}$ in photoreceptor axons. Scale bar, $20 \mu \mathrm{m}$. $E$, eye; $L$, lamina; $M$, medulla; arrow, terminations of photoreceptor cells 1-6; big arrowhead, termination of photoreceptor cells 7 and 8 .

creased staining (Fig. 6a). Elevated levels of Gi $\alpha$ were also detected in the ocellar retina and its projections (Fig. $4 c$ ) compared with Gs $\alpha$ (Fig. 4a) or Go $\alpha$ (Fig 4b) or Gi $\alpha$ in the brain neuropil (Fig. 4c). Gi $\alpha$ was also detected in the proximal half of the ocellar nerve (Fig. $4 c$ ). Moderate levels of staining above controls were detected in the compound eye retina. Neither the antennal nerve, the distal half of the ocellar nerve, or the first and second optic chiasma showed any staining. Additionally, complete sets of serial sections through the thoracic ganglion revealed no regions of elevated Gi $\alpha$. There was only partial competition of fat body and muscle staining by preincubation with the LD peptide; therefore, such staining could result from nonspecific binding.

To confirm the localization of the $\mathrm{Gi} \alpha$ homolog to regions of photoreceptor cell terminations from the compound eye, adjacent sections were stained with LD antibodies or antibodies to chaoptin (MAB 24B10; Vactor et al., 1988), which is restricted to photoreceptor cells and their projections into the brain (Fig. 7). Clearly, Gi $\alpha$ is associated with these nerve terminals, though it is completely absent from the nerve fibers leading to these terminals. At the light level, it is not possible to determine if $\mathrm{Gi} \alpha$ is primarily pre- or postsynaptic in either the lamina, medulla, or antennal glomeruli.

\section{Discussion}

Antibodies directed against peptide sequences specific to each form of $\mathrm{G} \alpha$ have been used in vertebrates to discriminate the forms of $\mathrm{G} \alpha$ expressed by specific cell types and to elucidate the function of specific domains in the $\mathrm{G} \alpha$ molecule. Three of these sequences (Goldsmith et al., 1988a, b) used to generate such antibodies (GO, RM, LD) are absolutely conserved in G $\alpha$ proteins expressed in Drosophila. This report describes the use of these antibodies to identify and localize $\mathrm{G} \alpha$ subunits in the nervous system of Drosophila.

The RM antibody is generated to a decapeptide sequence found at the C-terminus of vertebrate and Drosophila Gs $\alpha$. On Western blots, these antibodies recognize the expected multiple forms of $\mathrm{Gs} \alpha$ in bovine brain generated by alternate splicing of the transcript from a single gene (Bray et al., 1986). In Drosophila head membranes, the RM antibodies recognize a number of proteins larger than those found in vertebrates. Molecular cloning of cDNAs and the gene coding for Gs $\alpha$ in Drosophila predicts that the Gs $\alpha$ proteins should be larger than the vertebrate homologs and that multiple forms are also produced by alternate splicing of the transcript from a single gene (F. Quan and $\mathrm{M}$. Forte, unpublished observations). The GO antibody is directed to a decapeptide sequence found at the C-terminus of Go $\alpha$ in vertebrates and Drosophila. These antibodies recognize a single $39 \mathrm{kD}$ protein in both bovine brain and Drosophila head membranes. In addition, these antibodies have been shown to immunoprecipitate the pertussis toxin substrate present in the Drosophila nervous system (Thambi et al., 1989). Molecular cloning of cDNAs coding for Drosophila Go $\alpha$ homologs has indicated that 2 Go $\alpha$-like proteins differing at their $\mathrm{N}$-terminus are produced by alternate splicing of a single gene (Thambi et al., 1989). These proteins differ only slightly in molecular weight, and each contains the C-terminal GO peptide sequence. In situ hybridization with specific nucleic acid probes predicts the presence of both Go $\alpha$ proteins throughout the Drosophila nervous system (Thambi et al., 1989). For both the RM and GO antibodies, immunoreactive bands on Western blots are competed only by preincubation with the cognate peptide. Thus, all available evidence indicates that the RM and GO antibodies specifically recognize the Drosophila Gs $\alpha$ and Go $\alpha$ homologs.

In general, the distribution of $\mathrm{Gs} \alpha$ and $\mathrm{Go} \alpha$ in the adult Drosophila nervous system as determined by immunostaining is consistent with in situ hybridization studies using nucleic acid probes specific for these $\mathrm{G} \alpha$ s. Each is widely distributed in the nervous system and is present at high levels in all neuropils except the lamina. Intermediate levels appear in cortical regions. The abundance of Go $\alpha$ and Gs $\alpha$ in the neuropil regions is expected as these are sites of active intercellular communication. The distribution of Gs $\alpha$ and Go $\alpha$ in cell bodies differs in that Gs $\alpha$ appears to be associated with cell membranes, while Go $\alpha$ appears uniformly distributed throughout the cytoplasm. In vertebrates, quantitative immunoblotting and ultrastructural immunolocalization have suggested the existence of free, cytoplasmic Go $\alpha$ protein (Gierschik et al., 1986 a, b; Brabet et al., 1988; Gabrion et al., 1989). In addition, cytoplasmic Go $\alpha$ protein in chromaffin cells has been implicated in secretion (Toutant et al., 1987). Go $\alpha$ appears present as well in the fat body by both immunolocalization and in situ studies. Go $\alpha$ has also been found in fat cells of vertebrate tissues (Gierschik et al., 1986 a, 
b; Rapiejko, 1986; Rouot et al., 1987). Gs $\alpha$ and Go $\alpha$ appear absent or at low levels in the retina, lamina, and ocellus.

The LD antibodies are generated to a peptide sequence found roughly midway through vertebrate Gil $\alpha$ (Goldsmith et al., 1988a), which is completely conserved in Drosophila Gi $\alpha$ (Provost et al., 1988). On immunoblots of bovine brain membranes, these antibodies recognize the expected $41 \mathrm{kD}$ protein representing bovine Gil $\alpha$. Under these conditions, however, the LD antibodies, as well as other vertebrate $\mathrm{Gi} \alpha$-specific antibodies, fail to recognize any proteins on immunoblots of Drosophila head membranes. This result is almost ccrtainly due to the extremely low levels of Gi $\alpha$ found in the adult Drosophila nervous system. This interpretation is consistent with results obtained by Northern blot, indicating that transcripts coding for Gi $\alpha$ are preferentially expressed early in Drosophila development and at negligible levels in adult heads (Provost et al., 1988). In addition, in situ hybridization of $\mathrm{Gi} \alpha$ nucleic acid probes to sections of adult Drosophila heads failed to reveal any specific hybridization above background (Wolfgang, unpublished observations). The LD antibodies do recognize a protein of appropriate molecular weight for $\mathrm{Gi} \alpha$ in immunoblots of membranes from adult female abdomens, consistent with the observation that follicle cells secreting chorion have high levels of immunoreactivity (W. J. Wolfgang, A. Spiegel, and M. Forte, unpublished observations). Additionally, Drosophila Gi $\alpha$ expressed in $E$. coli is detected on Western blots by the LD antibody, confirming that this antibody recognizes Drosophila Gi $\alpha$.

On an immunocytochemical level, the LD antibodies preferentially stain very restricted regions of the Drosophila CNS, indicating a limited distribution for Gi $\alpha$ compared with Go $\alpha$ and Gs $\alpha$. This staining is competed only by preincubation of the LD antibodies with the cognate peptide and not with other, unrelated peptides. Elevated levels are found at the terminations of photoreceptor cells in the lamina and medulla. Additionally, staining is elevated in the ocellar retina and the antennal glomerulae which receive primary sensory input from olfactory receptors in the antennae. In the lamina and ocellar retina, little or no staining is observed for Gs $\alpha$ and Go $\alpha$. The distribution of $\mathrm{Gi} \alpha$ is then vastly different from that observed for Gs $\alpha$ and Go $\alpha$ and is almost complementary. In contrast, the distribution of Gs $\alpha$ and Gi2 $\alpha$ mRNAs in the rat were very similar but very different from that of Go $\alpha$ and Gil $\alpha$, mRNA (Brann et al., 1987). The finding that Gi $\alpha$ in the adult Drosophila nervous system is localized preferentially to regions of the brain containing either primary sensory afferents or their terminations suggests that the transduction of primary sensory information in the Drosophila brain is mediated either by a specific set of neurotransmitters and receptors or by the modulation of a specific effector pathway. Interestingly, no regions of elevated staining were detected in the thoracic ganglion despitc the abundance of cuticular mechanoreceptors terminations. Thus, some types of primary sensory information may be transduced without the involvement of Gi $\alpha$.

These antibodies, as well as others, will prove continually useful as specific reagents in the study of $\mathrm{G}$ proteins in Drosophila. They provide the ability to examine the expression of each Drosophila G protein $\alpha$ subunit during development in general and in the development of the nervous system specifically. Such studies are currently underway. The use of the LD antibodies will be particularly interesting since the development of the visual system in Drosophila is especially well described and is subject to modification by a number of mutations.

\section{References}

Brabet, P., A. Dumuis, M. Sebben, C. Pantaloni, J. Bockaert, and V. Homburger (1988) Immunocytochemical localization of the guanine nucleotide-binding protein Go in primary cultures of neuronal and glial cells. J. Neurosci. 8: 701-708.

Brann, M. R., R. M. Collins, and A. Spiegel (1987) Localization of mRNAs encoding the $\alpha$-subunits of signal-transducing $\mathrm{G}$ proteins within rat brain and among peripheral tissues. FEBS 222: 191-198.

Bray, P., A. Carter, C. Simons, V. Guo, C. Puckett, J. Kamholz, A. Spiegel, and M. Nirenberg (1986) Human cDNA clones for four species of Gs $\alpha$ signal transduction protein. Proc. Natl. Acad. Sci. USA 83: 8893-8897.

Brown, A. M., A. Yatani, J. Codina, and L. Birnbaumer (1989) G protein-gated channels: A third major category of ionic channels. Am. J. Hypertens. 2: 124-127.

Dietzel, C., and J. Kurjan (1987) The yeast SCGl gene: A G $\alpha$-like protein implicated in the $\alpha$ and $\alpha$-factor response pathway. Cell 50 . 1001-1010.

Gabrion, J., P. Brambet, B. Nguyin Than Dao, V. Homburger, A. Dumuis, M. Sebben, B. Rouot, and J. Bockaert (1989) Ultrastructural localization of the GTP-binding protein GO in neurons. Cell Signal. I: $107-123$.

Gierschik, P., B. Morrow, G. Milligan, C. Rubin, and A. Spiegel (1986a) Changes in the guanine nucleotide-binding proteins, $\mathrm{Gi}$ and Gol during differentiation of 3T3-L1 cells. FEBS 199: 103-106.

Gierschik, P., G. Milligan, M. Pines, P. Goldsmith, J. Codina, W. Klee, and A. Spiegel (1986b) Use of specific antibodies to quantitate the guanine nucleotide-binding protein Go in brain. Proc. Natl. Acad. Sci. USA 83: 2258-2262.

Gilman, A. G. (1984) G proteins and dual control of adenylate cyclase Cell 36: 577-579.

Goldsmith, P., P. Gierschik, G. Milligan, C. G. Unson, R. Vinitsky, H. Malech, and A. M. Spiegel (1987) Antibodies directed against synthetic peptides distinguish between GTP-binding proteins in neutrophil and brain. J. Biol. Chem. 262: 14683-14688.

Goldsmith, P., K. Rossiter, A. Carter, W. Simonds, C. G. Unson, R. Vinitsky, and A. M. Spiegel (1988a) Identification of the GTPbinding protein encoded by Gi3 complementary DNA. J. Biol. Chem. 263: 6476-6479.

Goldsmith, P., P. S. Backlund Jr., K. Rossiter, A. Carter, G. Milligan C. G. Unson, and A. M. Spiegel (1988b) Purification of heterotrimeric GTP-binding proteins from brain: Identification of a novel form of Go. Biochemistry 27: 7085-7090.

Itoh, H., T. Kozasa, S. Nagata, S. Nakanura, T. Katada, M. Ui, S. Iwai, S. Ohtsuka, H. Kawasaki, K. Suzuki, and Y. Kaziro (1986) Molecular cloning and sequence determination of cDNAs for $\alpha$ subunits of the guanine nucleotide-binding proteins $\mathrm{Gs}, \mathrm{Gi}$, and $\mathrm{Go}$ from rat brains. Proc. Natl. Acad. Sci. USA 83: 3776-3780.

Kumagai, A., M. Pupillo, R. Gunderson, R. Miake-Lye, P. Devreotes, and R. Firtel (1989) Regulation and function of $\mathrm{G} \alpha$ protein subunits in Dictyostelium. Cell 57: 265-275

McLean, I. W., and P. K. Nakane (1974) Periodate-lysine-paraformaldehyde fixative: A new fixative for immunoelectron microscopy. J. Histochem. Cytochem. 22: 1077-1093.

Miyajima, I., M. Nakafuku, N. Nakayama, C. Brenner, A. Miyajima, K. Kaibuchi, K. Arai, Y. Kaziro, and K. Matsumoto (1987) GPA1, a haploid-specific essential gene encodes a yeast homolog of mammalian $G$ protein which may be involved in mating factor signal transduction. Cell 50:1011-1019.

Neer, E. J., J. M. Lok, and L. G. Wolf (1984) Purification and properties of the inhibitory guanine nucleotide regulatory unit. J. Biol Chem. 259: 14222-14229.

Power, M. E. (1943) The brain of Drosophila melanogaster. J. Morphol. 72: 517-559.

Provost, N. M., D. E. Somers, and J. B. Hurley (1988) A Drosophila melanogaster $\mathrm{G}$ protein $\alpha$ subunit gene is expressed primarily in embryos and pupae. J. Biol. Chem. 263: 12070-12076.

Quan, F., W. Wolfgang, and M. Forte (1989) The Drosophila gene coding for the $\alpha$ subunit of a stimulatory $\mathrm{G}$ protein is preferentially expressed in the nervous system. Proc. Natl. Acad. Sci. USA 86: $4321-4325$

Rapiejko, P. J., J. K. Northup, T. Evans, J. E. Brown, and C. C. Malbon (1986) $G$ proteins of fat cells role in hormonal regulation of intracellular inositol 1,4,5-trisphosphate. Biochem. J. 240: 35-40. 
Rosenberg, A., B. Lade, C. Dao-shan, S. Lin, J. Dunn, and F. Studier (1987) Vectors for selective expression of cloned DNAs by T7 RNA polymerase. Gene 56: 125-135.

Rouot, B., P. Brabet, V. Homburger, M. Toutant, and J. Bockaert (1987) Go, a major brain GTP binding protcin in scarch of a function: Purification, immunological and biochemical characteristics. Biochimie 69: 339-349.

Spiegel, A. M. (1987) Signal transduction by guanine nucleotide binding proteins. Mol. Cell. Endocrinol. 49: 1-16.

Sternweis, P., and J. D. Robishaw (1984) Isolation of two proteins with high affinity for guanine nucleotides from membranes of bovine brains. J. Biol. Chem. 259:13806-13813.

Stausfeld, N. J. (1976) Atlas of an Insect Brain, Springer Verlag, New York.

Stryer, L., and H. Bourne (1986) G proteins: A family of signal transducers. Annu. Rev. Cell. Biol. 2:391-419.
Studier, F., and B. Moffatt (1986) Use of bacteriophage T7 RNA polymerase to direct selective high-level expression of cloned genes. J. Mol. Biol. 189: 113-130.

Toutant, M., D. Aunis, J. Bockaert, V. Homburger, and B. Rouot (1987) Presence of threc pertussis toxin substrates and Go $\alpha$ immunorcactivity in both plasma and granule membranes of chromaffin cells. FEBS 215: 339-344.

Thambi, N. C., F. Quan, W. J. Wolfgang, A. Spiegel, and M. Forte (1989) Immunological and molecular characterization of Go $\alpha$-like proteins in the Drosophila CNS. J. Biol. Chem. 264: 18552-18560.

Vactor, D. V. Jr., D. E. Krantz, R. Reinke, and S. L. Zipursky (1988) Analysis of mutants in chaoptin, a photoreceptor cell-specific glycoprotein in Drosophila, reveals its role in cellular morphogenesis. Cell 52: 281-290. 